\title{
Tinjauan Pelaksanaan Sistem Penyimpanan Rekam Medis Berdasarkan Standar Akreditasi Di UPTD Puskesmas Kotanopan Mandailing Natal
}

\author{
Zulham Andi Ritonga ${ }^{1}$, Hasran Ependi Lubis ${ }^{2}$ \\ ${ }^{1,2}$ Program Studi D-3 Perekam dan Informasi Kesehatan, Universitas Imelda Medan
}

\begin{tabular}{l} 
Article Info \\
\hline Article history: \\
Received Jan 12, 2021 \\
Revised Feb 18, 2021 \\
Accepted Feb 20, 2021 \\
\hline
\end{tabular}

Keywords:

Filing of Medical record Accreditation Of Public Health Centers

Medical Record

\begin{abstract}
ABSTRAK
Storage of medical records is one of the assessments in the puskesmas accreditation standard. The medical record file storage system is very important to do in health care institutions, because the storage system can make it easier for medical record files to be stored in storage racks, speed up the recovery or retrieval of medical record files stored on storage racks, easy to return, and protect record files. from theft, physical, chemical and biological damage. The purpose of this study was to determine how the implementation of a medical record storage system based on puskesmas accreditation standards, which was carried out in August 2020. The research method used was descriptive research with a qualitative approach. The number of research informants was 4 people. Storage of medical records had not used a tracer and expedition book as a means of replacing medical record files and notes in and out of borrowed medical record files. Meanwhile, tracer and expedition books can assist officers in searching for missing / out of place medical record files. This can hamper the provision of patient medical record files that are needed. It is hoped that the UPTD Puskesmas Kotanopan will provide regular training or debriefing to medical record officers.
\end{abstract}

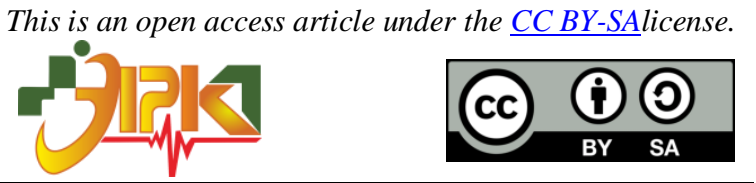

\section{Corresponding Author:}

Zulham Andi Ritonga,

Program Studi D-3 Perekam Medis dan Informasi Kesehatan,

Universitas Imelda Medan,

Jl. Bilal No. 52 Kelurahan Pulo Brayan Darat I Kecamatan Medan Timur, Medan - Sumatera Utara.

Email:zulhamandi16@gmail.com

\section{PENDAHULUAN}

Pusat Kesehatan Masyarakat ialah fasyankes yang menyelenggarakan upaya kesehatan masyarakat dan upaya kesehatan perorangan tingkat pertama yang bertugas melakukan upaya promotif dan preventif demi mencapai derajat kesehatan setinggi-tingginya. Puskesmas merupakan penyelenggara pelayanan kesehatan tingkat pertama yang dituju masyarakat dengan menyediakan pelayanan pasien rawat jalan, rawat inap dan darurat, sehingga ketika terdapat pasien gawat darurat harus segera mendapatkan pelayanan dan penanganan terlebih dahulu, agar dapat dilakukan pelayanan secara maksimal, maka sarana pelayanan kesehatan hendaknya menyelenggarakan rekam medis (Permenkes, 2014).

Berdasarkan Permenkes No 269 tahun 2008, Rekam Medis merupakan berkas berisi dokumen dan catatan tentang identitas pasien, pengobatan, pemeriksaan, tindakan dan 
pelayanan lain yang telah diberikan kepada pasien. Keberadaan rekam medis sangat dibutuhkan untuk mendukung pelaksanaan kegiatan pelayanan kesehatan. Setiap layanan kesehatan pada pasien semestinya dicatat pada berkas rekam medis agar terwujud data rekam medis yang berkesinambungan. Pasal 12 (1) Permenkes No 269 tahun 2008, disebutkan bahwa berkas rekam medis milik sarana yankes. Artinya sarana pelayanan kesehatan memiliki tanggung jawab utuh dalam memelihara, menjaga dan menyediakan berkas RM kembali saat dibutuhkan oleh petugas kesehatan, pasien maupun pihak lain pada fasyankes yang ada. Berkas RM mempunyai fungsi untuk melindungi petugas medis dan non medis sewaktu terjadi masalah hukum. Oleh karena itu, sarana pelayanan kesehatan seperti petugas rekam medis harus bias mengurangi masalah yang terjadi di bagian rekam medis.

Pengelolaan RM pada Puskesmas yaitu teknik penomoran, penataan, penyimpanan, pelaporan, pemilahan berkas dan pemusnahan. Pemberian nomor RM menggunakan kode yang berbeda untuk setiap kelurahan yang ada pada wilayah kerja puskesmas atau yang ada di luar wilayah kerja puskesmas. Kegiatan assembling dilakukan oleh petugas untuk menyusun lembaran formulir RM dan menganalisa pencatatan yang lengkap. Petugas menyimpan berkas rekam medis sesuai nomor pada lemari penyimpanan. Pelaporan RM dapat dilakukankan setiap hari atau bulanan. Berkas RM setelah jangka waktu lama tidak digunakan akan di retensi dan dimusnakan sesuai prosedur yang ada (Yulia, 2019).

Sistem penyimpanan berdasarkan lokasi penyimpanan terdiri dari sentralisasi dan desentralisasi. Sedangkan berdasarkan cara penjajaran dibagi menjadi 3 yaitu, Straight Nmerical Filing (SNF) atau sistem penomoran langsung; Midle Digit Filing (MDF) atau sistem angka tengah; Terminal Digit Filing (TDF) atau menggunakan angka akhir (Budi, 2011).

Akreditasi merupakan pengakuan oleh lembaga independen penyelenggara akreditasi dan ditetapkan oleh mentri setelah memenuhi standar akreditasi (PMK NO.46 2015). Permenkes RI No. 75 Tahun 2014 pasal 39 ayat (1), mewajibkan Puskesmas terakreditasi secara periodik minimal 3 tahun sekali, dimana akreditasi merupakan salah satu persyaratan kredensial sebagai faskes tingkat primer dan bekerjasama dengan BPJS, sebagaimana diatur dalam Permenkes RI No. 71 tahun 2013 tentang Pelayanan Kesehatan Pada Jaminan Kesehatan Nasional Pasal 6 ayat (2).

Berdasarkan penelitian yang dilakukan oleh (Valentina, 2019) di Puskesmas Sukaramai menyatakan akreditas berdampak pada peningkatan mutu kualitas pelayanan salah satunya yaitu pada sistem penyimpanan rekam medis. Sistem filing RM pada Puskesmas Sukaramai mengadopsi family folder, penjajaran RM menggunakan Straight Numerical Filling (SNF), pengambilan BRM selalu dilakukan oleh petugas lain yang tidak petugas rekam medis, tidak adanya penggunaan tracer, peminjaman BRM tidak menggunakan buku ekspedisi serta sistem pengembalian BRM tidak dipulangkan pada akhir jam kerja. Hal ini akan menyebabkan terjadinya informasi yang tidak berkesinambungan.

Berdasarkan hasil survei awal yang telah dilakukan bahwa Puskesmas Kotanopan sudah terakreditasi dengan status madya pada tahun 2018 dan sistem pengolahan yang digunakan adalah sistem sentralisasi yang mana rekam medis rawat jalan dan rawat inap disatukan dalam satu ruangan filing dengan sistem penomoran family folder yaitu 1 BRM digunakan oleh 1 keluarga yang diberikan kode khusus pada setiap folder. Sedangkan sistem penyimpanan yang digunakan adalah sistem penyimpanan langsung (Straight Numerical Filing) yaitu sistem penyimpanan BRM dengan menjajarkan BRM sesuai urutan nomor RM nya secara langsung pada rak penyimpanan.

Dalam pelaksanaan penyimpanan masih ditemukan kekeliruan penyimpanan (missfile) karena belum menggunakan tracer sebagai alat kendali keluar masuknya berkas RM pada rak penyimpanan dan tidak adanya buku ekspedisi peminjaman berkas RM sehingga tidak 
diketahui siapa yang meminjam dan menerimanya. Hal tersebut menghambat penyediaan berkas RM yang dibutuhkan cepat, selain itu berkas RM yang dicari tidak ditemukan sehingga petugas harus membuat berkas rekam medis baru dan jika sudah ditemukan maka berkas RM yang baru dan yang lama akan disatukan. Menurut uraian permasalahan di atas, maka dilakukan penelitian dengan judul "Tinjauan Sistem Penyimpanan Rekam Medis Menurut Standar Akreditasi di Pusekesmas Kotanopan".

\section{METODE PENELITIAN}

A. Jenis Penelitian

Jenis penelitian ini menggunakan metode penelitian kualitatif. Metode penelitian kualitatif ialah suatu penelitian ilmiah bertujuan untuk memahami fenomena dalam kontak sosial secara alamiah dengan mendahulukan proses interaksi komunikasi secara mendalam antara peneliti terhadap fenomena yang diteliti (Haris, 2010).

B. Lokasi Dan Waktu Penelitian

Penelitian ini dilakukan di UPTD Puskesmas Kotanopan Wilayah kerja meliputi semua kelurahan dan desa yang berada di Kecamatan Kotanopan pada bulan Juli sampai dengan Agustus 2020.

C. Subjek Penelitian

Subjek penelitian adalah sumber informasi pada penelitian yang dibutuhkan untuk pengumpulan data (Maleong, 2012). Adapun subjek penelitian ini ialah petugas rekam medis, sistem penyimpanan rekam medis, prosedur penyimpanan rekam medis, dan fasilitas penyimpanan rekam medis.

D. Informan Penelitian

Adapun jumlah Informan dalam penelitian ini ialah 4 orang petugas rekam medis, diantaranya kepala rekam medis sebanyak 1 orang dan petugas pelaksana sebanyak 3 orang.

E. Instrumen Penelitian

Instrumen penelitian ialahfasilitas atau alat yang digunakan oleh peneliti dalam mengumpulkan data agar pekerjaan lebih mudah dan hasilnya lebih baik (lengkap, cermat dan sistematis) sehingga lebih mudah diolah (Saryono, 2010). Instrumen pada penelitian ini ialah:

1. Pedoman wawancara

Merupakan daftar pertanyaan yang telah dibuat oleh peneliti sebelum melakukan penelitian. Wawancara adalah suatu metode yang berguna untuk mengumpulkan data, dimana peneliti mendapatkan keterangan atau perincian secara lisan dari responden (Notoatmodjo, 2010).

2. Lembar observasi

Merupakan daftar ceklist yang dibuat oleh peneliti untuk mengamati keadaan yang terjadi di lapangan dalam melakukan suatu penelitian, yaitu dalam pelaksanaan sistem penyimpanan berkas RM (Notoadmodjo, 2011).

F. Jenis dan Metode Pengumpulan Data

1. Data primer

Data primer ialah data yang diperoleh langsung dari subjek penelitian dengan melakukan wawancara untuk memperoleh informasi tentang sistem penyimpanan berkas RM.

2. Data sekunder

Data sekunder adalah data yang didapat oleh hasil pengamatan atau studi Dokumentasi tentang system penyimpanan berkas RM, penelitian sebelumnya, dokumen dan lain-lain. 
G. Teknik Analisis Data

1. Reduksi data

Reduksi data yaitu membuat rangkuman, memilih hal pokok, memfokuskan pada hal-hal penting, mencari tema dan pola, serta membuang yang dianggap tidak perlu. Dengan kata lain, pada tahap ini dilakukan analisis untuk menggolong-golongkan data, direduksi data yang tidak perlu, mengarahkan, dan mengorganisasikan data.

2. Penyajian data

Penyajian data yaitu gabungan informasi tersusun yang memberikan adanya kemungkinan penarikan kesimpulan dan pengambilan tindakan. Data wawancara dan hasil observasi disajikan dalam bentuk narasi atau tekstular

3. Verifikasi data

Verifikasi data yaitu menarik kesimpulan berdasarkan hasil temuan dan data yang didapatkan selama penelitian.

\section{HASIL DAN PEMBAHASAN}

\subsection{Hasil}

\section{Informan Penelitian}

Informan 1 berjenis kelamin perempuan, berumur 43 tahun dengan tingkat pendidikan D-III Kebidanan dimana lama kerjanya 3 tahun. Informan 2 berjenis kelamin perempuan dan berumur 30 tahun dengan tingkat pendidikan D-III Kebidanan dimana lama kerjanya 2 tahun. Informan 3 berjenis kelamin perempuan, berumur 30 tahun dengan tingkat pendidikan D-III Kebidanan dimana lama kerjaanya 2 tahun. Informan 4 berjenis kelamin laki-laki dan berumur 31 tahun dengan tingkat pendidikan D-III Keperawatan dimana lama kerjanya 1 tahun.

Tabel 1. Informan Penelitian di UPTD Puskesmas Kotanopan Tahun 2020

\begin{tabular}{cccccc}
\hline No & $\begin{array}{c}\text { Informan } \\
\text { Penelitian }\end{array}$ & Jenis Kelamin & Usia & Pendidikan & Lama Kerja \\
\hline 1 & Informan 1 & Perempuan & 43 tahun & D-III Kebidanan & 3 tahun \\
\hline 2 & Informan 2 & Perempuan & 30 tahun & D-III Kebidanan & 2 tahun \\
\hline 3 & Informan 3 & Perempuan & 30 tahun & D-III Kebidanan & 2 tahun \\
\hline 4 & Informan 4 & Laki - laki & 31 tahun & D-III Perawat & 1 tahun \\
\hline
\end{tabular}

\section{Sistem Penyimpanan Berkas RM}

Berdasarkan hasil observasi penyimpanan berkas RM pada UPTD Puskesmas Kotanopan menggunan sistem penyimpanan Family Folder, dikelola secara Sentralisasi menggunakan sistem penjajaran Straight Numerical Filling (SNF) serta menggunakan kode wilayah, penomoran berkas rekam medis menggunakan Numeric. Secara terperinci dapat dilihat pada tabel 2 sebagai berikut:

Tabel 2. Hasil Observasi Sistem Penyimpanan Berkas Rekam Medis di UPTD Puskesmas Kotanopan Tahun 2020

\begin{tabular}{|c|c|c|c|c|}
\hline No & Observasi & $\mathbf{Y a}$ & Tidak & Keteranagan \\
\hline 1 & $\begin{array}{l}\text { Penyimpanan } \\
\text { berdasarkan } \\
\text { lokasi }\end{array}$ & $\checkmark$ & & $\begin{array}{l}\text { UPTD Puskesmas Kotanopan Menggunakan } \\
\text { sistem peyimpanan Family Folder yaitu satu } \\
\text { berkas rekam medis digunakan oleh satu } \\
\text { keluarga tetapi belum terdapat tambahan kode } \\
\text { khusus untuk ayah, ibu, dan anak. Menggunakan } \\
\text { penyimpanan sesuai lokasi yaitu sentralis UPTD } \\
\text { Puskesmas Kotanopan Menggunakan sistem }\end{array}$ \\
\hline
\end{tabular}


peyimpanan Family Folder yaitu satu berkas rekam medis digunakan oleh satu keluarga tetapi belum terdapat tambahan kode khusus untuk ayah, ibu, dan anak. Menggunakan penyimpanan sesuai lokasi yaitu sentralisasiasi.

UPTD Puskesmas Kotanopan menggunakan sistem penjajaran Stright Numerical Filing (SNF) yang mana berkas rekam medis dijajarkan berdasarkan urutan langsung nomor rekam medisnya pada rak penyimpanan.

\begin{tabular}{lll}
\hline $\begin{array}{l}\text { Penomoran } \\
\text { berkas rekam } \\
\text { medis }\end{array}$ & $\checkmark$ & $\begin{array}{l}\text { Berkas rekam medis di UPTD Puskesmas } \\
\text { menggunakan sistem penomoran Numeric. }\end{array}$ \\
\hline
\end{tabular}

\section{Prosedur Penyimpanan Berkas RM}

Hasil observasi yang dilakukan oleh peneliti menunjukkan bahwa pengambilan dan penyimpanan berkas RM di ruang penyimpanan hanya petugas rekam medis, sedangkan pengembalian berkas rekam medis bisa dilakukan selain petugas rekam medis. Secara terperinci dilihat pada tabel 3 dibawah ini:

Tabel 3. Hasil Observasi Prosedur Penyimpanan Berkas Rekam Medis di UPTD Puskesmas Kotanopan Tahun 2020

\begin{tabular}{rlccl}
\hline No & \multicolumn{1}{c}{ Observasi } & Ya & Tidak & \multicolumn{1}{c}{ Keterangan } \\
\hline 1 & $\begin{array}{l}\text { Pengambilan berkas rekam } \\
\text { medis dilakukan selain } \\
\text { petugas }\end{array}$ & & $\checkmark$ & $\begin{array}{l}\text { Ruang penyimpanan rekam } \\
\text { medis sudah dilindungi dari akses } \\
\text { yang tidak berhak. }\end{array}$ \\
\hline 2 & $\begin{array}{l}\text { Pengembalian berkas } \\
\text { dilakukan selain petugas }\end{array}$ & $\checkmark$ & & $\begin{array}{l}\text { Kadang berkas rekam medis } \\
\text { dikembalikan oleh perawat dari } \\
\text { poli. }\end{array}$ \\
\hline 3 & $\begin{array}{l}\text { Penyimpanan berkas rekam } \\
\text { medis dilakukan selain } \\
\text { petugas }\end{array}$ & $\checkmark$ & $\begin{array}{l}\text { Yang berhak menyimpan berkas } \\
\text { rekam medis hanya petugas } \\
\text { rekam medis. }\end{array}$ \\
\hline
\end{tabular}

\section{Fasilitas Penyimpanan Berkas RM}

Berdasarakan hasil observasi bahwa di ruang penyimpanan terdapat Map Berkas RM, Tangga, dan Rak penyimpanan, sedangkan Tracer dan Buku Ekspedisi tidak tersedia. Secara terperinci dilihat pada tabel 4 berikut ini:

Tabel 4. Hasil Observasi Fasilitas Penyimpanan Berkas Rekam Medis di UPTD Puskesmas Kotanopan Tahun 2020

\begin{tabular}{clccl}
\hline No & Observasi & Ya & Tidak & Keterangan \\
\hline 1 & Tracer & & $\checkmark$ & Tidak Menggunakan Tracer \\
\hline 2 & Buku Ekspedisi & & $\checkmark$ & Tidak meggunakan Buku Ekspedisi \\
\hline 3 & MapBerkas RM & $\checkmark$ & & Menggunakan Map \\
\hline 4 & Tangga & $\checkmark$ & & Menggunakan Tangga \\
\hline 5 & Rak Penyimpanan & $\checkmark$ & & Mengunakan Rak Penyimpanan \\
\hline
\end{tabular}


Hasil Wawancara

Pertanyaan 1, Bagaimana sistem penyimpanan berkas RMpada UPTD Puskesmas Kotanopan?

Menurut saya sistem penyimpanan berkas RM disini belum sesuai pada standar yang berlaku, karena masih sering kehilangan status (informan 1).

Sistem penyimpanan $R M$ sudah rapi dan tertata di tiap rak (informan 2).

Sebetulnya saya kurang faham tentang rekam medis ini, jadi menurut saya sudah bagus (informan 3).

Sesuai dengan hasil wawancara dengan informan menjelaskan bahwa sistem penyimpanan RM di UPTD Puskesmas Kotanopan belum sesuai dengan SOP dan Akreditasi Puskesmas.

Pertanyaan 2, Jelaskan bagaimana prosedur penyimpanan RM pada UPTD Puskesmas Kotanopan?

Prosedurnya ya kalo ada pasien yang datang berobat atau sudah mendaftar, berkas statusnya langsung diambil dan di serahkan ke poli, tetapi tetap berpedoman dengan SOP yang berlaku (informan 1)

Saya langsung ambil saja statusnya berdasarkan no rm yang dikasih dan mengantarnya ke poli tujuan (informan 4 )

Sesuai dengan hasil wawancara dengan informan prosedur penyimpanan rekam medis sudah sesuai dengan SOP yang berlaku di UPTD Puskesmas Kotanopan.

Pertanyaan 3, Apakah berkas rekam medis selalu dikembalikan ke ruang penyimpanan pada saat akhir jam kerja atau pasien rawat inap pulang?

$Y a$, kalau berkas rawat jalan setiap akhir jam kerja pasti diantar perawat poli lagi balik ke sini, kadang kalau tidak dikembalikan kami akan menjemputnya (informan 1).

Sesuai dengan hasil wawancara dengan informan pengembalian berkas rekam medis selalu seuai dengan prosedur atau SOP yang ada di UPTD Puskesmas Kotanopan.

Pertanyaan 4, Siapa saja yang dapat mengakses berkas di ruang penyimpanan rekam medis?

Yang dapat mengakses atau mengambil berkas RM di ruang penyimpanan hanya petugas filling/ penyimpanan saja, saya selalu tegas akan hal itu karena menyangkut kerahasiaan data pasien" (Informan I).

Sesuai dengan hasil wawancara dengan informan yang dapat mengakses berkas di ruang penyimpanan hanya petugas rekam medis saja.

Pertanyaan 5, Apa saja alat bantu yang dipergunakan saat mencari berkas rekam medis?

Sejauh ini kami masih menggunakan cara manual dalam mencari berkas di rak (informan 3).

Apabila berkas status tidak ada di rak kami akan membuat berkas yang baru (informan 2).

Sesuai dengan hasil wawancaradengan informan tidak ada alat bantu yang dipergunakan saat mencari berkas rekam medis, seharusnya harus ada Tracer dan Buku ekspedisi.

Pertanyaan 6, Apa saja fasilitas yang ada untuk mendukung pelaksanaan penyimpanan berkas RM pada UPTD Puskesmas Kotanopan?

Tangga, untuk mengambil status yang di rak tinggi (informan 4).

Ruangan, rak, map status, (informan 3). 
Berdasarkan hasil wawancara dengan infoman fasilitas yang ada untuk mendukung pelaksanaan penyimpanan rekam medis adalah tangga, rak, dan map berkas rekam medis.

Pertanyaan 7, Apa saja kendala yang anda alami saat mencari berkas rekam medis?

Kalau memang berkasnya ada di rak tidak ada kendala dalam mencarinya, tapi kadang ada juga berkas lama yang hilang akibatnya kami harus membuat yang baru (informan 1). Ketinggian raknya kadang menyusahkan pengambilan status (informan 4).

Kendalanya kadang tempat status pasien tidak tepat peletakannya (informan 3).

Berdasarkan hasil wawancara dengan informan adapun masalah yang dialami oleh petugas adalah sering terjadi kehilangan berkas rekam medis/missfile saat mencari berkas rekam medis.

\subsection{Pembahasan}

\section{Sistem Penyimpanan Berkas RM}

Sesuai dengan hasil observasi dan wawancara penyimpanan berkas RM pada UPTD Puskesmas Kotanopan menggunan sistem penyimpanan Family Folder, dikelola secara Sentralisasi menggunakan sistem penjajaran Straight Numerical Filling (SNF) serta menggunakan kode wilayah, penomoran berkas rekam medis menggunakan Numeric.

Menurut pendapat (Budi, 2011), bahwa jenis sistem penjajaran yang sesuai dengan family folder adalah sistem penjajaran Terminal Digit Filing (TDF) yang dikelola secara sentralisasi. Adapun hasil dari observasi dan wawancara di UPTD Puskesmas Kotanopan masih menggunakan sistem penjajaran Straight Numerical Filling (SNF) yang berakibat terjadinya pertukaran nomor urut berkas rekam medis (missfile).

Dari uraian diatas peneliti dapat menyimpulkan bahwa sistem penyimpanan berkas RM pada UPTD Puskesmas Kotanopan menggunan Straight Numerical Filing tetapi kebanyakan fasilitas kesehatan banyak menggunakan sistem Terminal Digit Filling (TDF) dikarenakan mempunyai kelebihan dalam pencarian berkas selanjutnya sistem penyimpanan menggunakan family folder akan tetapi secara teoritis menggunakan numeric dan alfanumeric.

\section{Posedur Penyimpanan Berkas RM}

Berdasarkan observasi dan wawancara pengembalian berkas RM pada UPTD Puskesmas Kotanopan selalu dilakukan diakhir jam kerja pada pasien rawat jalan dan setelah pasien pulang pada pasien rawat inap, sesuaidengan teori (Riyanto, 2012) pada peminjaman semestinya membuat ketentuan berapa jangka lama waktu untuk 1 RM diizinkan tidak terdapat pada rak penyimpanan. Semestinya setiap dokumen RM kembali pada setiap akhir hari kerja.

Pengembalian yang tidak sesuai dengan ketentuan dapat mengakibatkan missfile pada sistem penyimpanan, dan petugas filling pada keesokan harinya menjadi kewalahan karena harus menyusun berkas yang harus dikembalikan dan juga petugas filing harus mencari berkas pasien yang berobat saat itu. Sehingga akan terjadi penumpakan pasien pada pendaftaran.

\section{Fasilitas Penyimpanan Berkas RM}

Sesuai dengan observasi dan wawancara fasilitas pada ruangan penyimpanan dijumpai Tangga, Rak, dan Map berkas RM sedangkan Tracer dan Buku Ekspedisi belum ada dikarenakan kurangnya pemahaman dan latar belakang pendidikan petugas RM pada UPTD Puskesmas Kotanopan yang tidak berlatarkan dari pendidikan perekam medis dan informasi kesehatan, hal ini tidak sesuai dengan teori pengambilan berkas (Rustiyanto \& 
Rahayu, 2011) yang berakibat missfile karena petugas tidak tau berkas RM itu berada di poli mana.

\section{KESIMPULAN}

Berdasarkan hasil dari pembahasan penelitian yang berjudul Tinjauan Pelaksanaan Sistem Penyimpanan RM. Berdasarkan Akreditasi di UPTD Puskesmas Kotanopan dapat ditarik kesimpulan sebagai berikut:

1. Petugas RM pada UPTD Puskesmas Kotanopan belum ada yang berkualifikasi pendidikan Perekam Medis dan Informasi Kesehatan.

2. Sistem penyimpanan yang dilakukan pada UPTD Puskesmas Kotanopan menggunakan family folder, penjajaran BRM menggunakan Straight Numerical Filing (SNF).

3. Prosedur pengambilan berkas RM sudah dilindungi dari akses yang tidak berhak atau selain petugas rekam medis.

4. Prosedur pengembalian berkas RM selalu dipulangakan pada akhir jam kerja atau pada saat pasien rawat inap pulang.

5. Fasilitas penyimpanan di UPTD Puskesmas Kotanopan belum menggunakan treacer untuk pengganti sementara pengambilan berkas rekam medis, dan juga belum menggunakan buku ekspedisi untuk peminjaman dan pemulangan berkas rekam medis.

\section{REFERENCES}

Budi, S Citra. 2011. Manajemen Unit Kerja Rekam Medis. Yogyakarta: Quantum Sinergis Media.

Hatta, Gemala R. 2014. Pedoman Manajemen Informasi Kesehatan Disarana Pelayanan Keseshatan. Jakarta: Universitas Indonesia (UI-Press).

Isgiyanto, Awal. 2009. Teknik Pengambilan Sampel. Yogyakarta: Mitra Medika.

Isminar, Hetty. 2015. Manajemen Unit Kerja. Yogyakarta: Deepublish.

Mamyoito, H. 2018. Tinjauan Sistem Penyimpanan Rekam Medik Menurut Akreditasi Puskesmas di Puskesmas Sukaramai. KTI APIKES Imelda. Medan.

Menteri Kesehatan Republik Indonesia. 2004. Standart Akreditasi Puskesmas. Jakarta: Kementerian Kesehatan.

Peraturan Menteri Kesehatan RI No.269 Tahun 2009. Tentang Rekam Medis.

Peraturan Menteri Kesehatan RI No.55 Tahun 2013. Tentang Penyelenggaraan Pekerja Perekam Medis.

Peraturan Menteri Kesehatan RI No.75 Tahun 2014.Tentang Pusat Kesehatan Masyarakat. Jakarta: Menteri Kesehatan Republik Indonesia.

Peraturan Menteri Kesehatan RI No.13 Tahun 2015. Tentang Penyelenggaraan Pelayanan Kesehatan Lingkungan di Puskesmas.

Peraturan Menteri Kesehatan RI No.46 Tahun 2016. tentang Akreditasi Puskesmas, Klinik Pratama, Tempat Praktik Mandiri Dokter, Dan Tempat Praktik Mandiri Dokter Gigi. 
Notoatmojo S. 2015. Metodologi Penelitian Kesehatan. Yogyakarta: Rineka Cipta.

Rustiyanto E dan Rahayu W Ambar. 2004. Manajemen Filing Dokumen Rekam Medis dan Informasi Kesehatan. Yogyakarta: Poltekkes Permata Indonesia.

Riyanto, Budi. 2012. Tinjauan Pelaksanaan Penyimpanan Dan Pengambilan Dokumen Rekam Medis di Bidang Filing RSUD Kabupaten Karanganyar Tahun 2012. Rekam Medis. Vol.6. No.2. Oktober 2012: 50-58.

Valentina. (2019). Tinjauan Sistem Penyimpanan Rekam Medis Menurut Standar Akreditasi Puskesmas Di Puskesmas Sukaramai Tahun 2019. Jurnal Ilmiah Perekam Dan Informasi Kesehatan Imelda, 4(1), 554-559. https://jurnal.uimedan.ac.id/index.php/JIPIKI/article/view/76.

\section{BIOGRAPHIES OF AUTHORS}

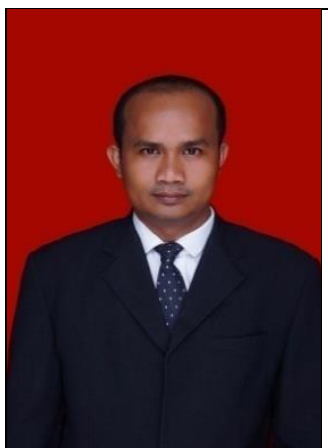

Zulham Andi Ritonga, Gelar D3 dipeoleh dari AKPER Imelda Medan tamat tahun 2003, S1 dari Fakultas Kesehatan Masyarakat Universitas Sumatera Utara minat studi Administrasi Kebijakan Kesehatan tamat pada tahun 2011, dan S2 dari Fakultas Kesehatan Masyarakat Universitas Sumatera Utara minat studi Administrasi Rumah Sakit tamat tahun 2019. Saat ini staf pengajar di D-3 Perekam Medis dan Informasi Kesehatan Universitas Imelda Medan. 